\title{
In Vitro Pharmacologic Restoration of CFTR-mediated Chloride Transport with Sodium 4-Phenylbutyrate in Cystic Fibrosis Epithelial Cells Containing $\Delta$ F508-CFTR
}

\author{
Ronald C. Rubenstein, Marie E. Egan, ${ }^{\star}$ and Pamela L. Zeitlin \\ Eudowood Division of Pediatric Respiratory Sciences, The Johns Hopkins Hospital, Baltimore, Maryland 21287; and *Section of \\ Pediatric Respiratory Medicine, Yale University, New Haven, Connecticut 06520
}

\begin{abstract}
The most common cystic fibrosis transmembrane conductance regulator mutation, $\Delta \mathrm{F} 508-\mathrm{CFTR}$, is a partially functional chloride channel that is retained in the endoplasmic reticulum and degraded. We hypothesize that a known transcriptional regulator, sodium 4-phenylbutyrate (4PBA), will enable a greater fraction of $\Delta$ F508-CFTR to escape degradation and appear at the cell surface. Primary cultures of nasal polyp epithelia from CF patients ( $\Delta$ F508 homozygous or heterozygous), or the $\mathrm{CF}$ bronchial epithelial cell line IB3-1 ( $\Delta$ F508/W1282X) were exposed to 4PBA for up to $7 \mathrm{~d}$ in culture. 4PBA treatment at concentrations of 0.1 and $2 \mathrm{mM}$ resulted in the restoration of forskolin-activated chloride secretion. Protein kinase A-activated, linear, 10 pS chloride channels appeared at the plasma membrane of IB3-1 cells at the tested concentration of $2.5 \mathrm{mM}$. Treatment of IB3-1 cells with 0.1-1 mM 4PBA and primary nasal epithelia with $5 \mathrm{mM} 4 \mathrm{PBA}$ also resulted in the appearance of higher molecular mass forms of CFTR consistent with addition and modification of oligosaccharides in the Golgi apparatus, as detected by immunoblotting of whole cell lysates with antiCFTR antisera. Immunocytochemistry in CF epithelial cells treated with 4PBA was consistent with increasing amounts of $\triangle$ F508-CFTR. These data indicate that 4PBA is a promising pharmacologic agent for inducing correction of the $\mathrm{CF}$ phenotype in CF patients carrying the $\Delta$ F508 mutation. ( $J$. Clin. Invest. 1997. 100:2457-2465.) Key words: cystic fibrosis • CFTR • phenylbutyrate • pharmacotherapy
\end{abstract}

\section{Introduction}

Cystic fibrosis $(\mathrm{CF})^{1}$ is a systemic disorder that results when mutations in the cystic fibrosis transmembrane conductance regulator (CFTR), an apical membrane glycoprotein, lead to a reduction in apical membrane chloride transport. CFTR is a cAMP-dependent chloride channel that regulates fluid compo-

Address correspondence to Ronald C. Rubenstein, M.D., Ph.D., Pediatric Pulmonary, The Johns Hopkins Hospital-Park 316, $600 \mathrm{~N}$. Wolfe St., Baltimore, MD 21287. Phone: 410-955-2035; FAX: 410955-1030; E-mail: rrubenst@welchlink.welch.jhu.edu

Received for publication 28 May 1997 and accepted in revised form 16 September 1997.

J. Clin. Invest.

(C) The American Society for Clinical Investigation, Inc. 0021-9738/97/11/2457/09 \$2.00

Volume 100, Number 10, November 1997, 2457-2465

http://www.jci.org sition in the respiratory and gastrointestinal tracts. In CF, unusually thick mucus leads to recurrent airway and intestinal obstruction, as well as chronic respiratory infection.

$70 \%$ of the mutant CFTR alleles in the Caucasian population result from deletion of phenylalanine at position 508 $(\Delta$ F508-CFTR). This mutation results in a protein capable of conducting chloride (1-4), but absent from the plasma membrane because of aberrant intracellular processing (5). Under usual conditions at $37^{\circ} \mathrm{C}, \Delta \mathrm{F} 508-\mathrm{CFTR}$ is retained in the endoplasmic reticulum (ER), perhaps by prolonged association with the ER chaperones calnexin (6) and hsp70 (7), and is then targeted for degradation by the ubiquitin/proteasome pathway $(8,9)$. There is one published report that by overexpression of $\Delta$ F508-CFTR, functional $\Delta$ F508-CFTR protein can be measured at the cell surface. This work used $\Delta \mathrm{F} 508$-homozygous $\mathrm{CF}$ airway and immortalized pancreatic cells treated with the transcriptional regulator butyrate (10), a prototype drug with considerable toxicity and a half-life necessitating intravenous administration (11).

The $\Delta$ F508 "trafficking" block is also reversible by incubation of cultured CF epithelial cells at reduced temperatures $\left(25-27^{\circ} \mathrm{C}\right)$. In a time-dependent manner, lowered temperature results in the appearance of CFTR protein and channel activity at the cell surface (12). This observation suggests an intrinsic thermodynamic instability in $\triangle \mathrm{F} 508$-CFTR at $37^{\circ} \mathrm{C}$ that leads to recognition of the mutant protein by the ER quality control mechanism, prevents further trafficking, and results in protein degradation. Thermal stabilization may allow the protein to assume the appropriate conformation for normal trafficking. High concentrations of glycerol (1 M or 10\%), a protein stabilizing agent or "chemical chaperone," also appears to facilitate movement of $\Delta \mathrm{F} 508$-CFTR from the ER to the plasma membrane $(13,14)$.

Our goal is to identify nontoxic, clinically useful compounds that will increase the amount of $\Delta$ F508-CFTR on the surface epithelium of patients with CF. Sodium 4-phenylbutyrate (4PBA) is a butyrate analogue that is approved for clinical use as an ammonia scavenger in subjects with urea cycle disorders. It is also a known transcriptional regulator of $\beta$ - and $\gamma$-globin (15) that may act by inhibiting histone deactylase (16). The hypothesis of this study is that 4PBA will promote $\Delta$ F508-CFTR trafficking to the cell surface.

1. Abbreviations used in this paper: $\mathrm{CF}$, cystic fibrosis; CFTR, cystic fibrosis transmembrane conductance regulator; $\Delta$ F508-CFTR, cystic fibrosis transmembrane conductance regulator containing a deletion of phenylalanine at position 508; ER, endoplasmic reticulum; 4PBA, sodium 4-phenylbutyrate; PKA, cAMP-dependent protein kinase; W1282X, mutation of tryptophan at position 1282 to a termination codon. 


\section{Methods}

Cell culture. Primary CF nasal epithelial cells were isolated from surgical specimens and grown in tissue culture flasks coated with vitrogen/fibronectin/bovine serum albumin using modifications of previously described procedures (17). IB3-1 cells (17) were grown on uncoated plastic supports or, for immunocytochemistry, on coated glass cover slips. Cells were routinely cultured in $5 \% \mathrm{CO}_{2}$ incubators in LHC-8 (Biofluids, Inc., Rockville, MD) supplemented with 5\% fetal bovine serum (Sigma Chemical Co., St. Louis, MO), 100 U/ml penicillin/streptomycin (GIBCO BRL, Gaithersburg, MD), $0.2 \mathrm{mg} / \mathrm{ml}$ Primaxin (imipenim; Merck and Co., West Point, PA), $80 \mu \mathrm{g} / \mathrm{ml}$ tobramycin (Eli Lilly \& Co., Indianapolis, IN), and $2.5 \mu \mathrm{g} / \mathrm{ml}$ fungizone (Biofluids, Inc.). Cells for control experiments were cultured under routine conditions described above. Growth medium for the treated cells was comprised of the indicated agent at the indicated concentration added to the routine growth medium and incubated in a $5 \% \mathrm{CO}_{2}$ atmosphere.

Chloride efflux. Chloride efflux experiments were performed essentially as described by Trapnell et al. (18). Briefly, cells were seeded in coated $35-\mathrm{mm}$ dishes under the indicated conditions and grown to $80-90 \%$ confluence. Cells were loaded with $3 \mu \mathrm{Ci} / \mathrm{dish}$ of $\mathrm{Na}^{36} \mathrm{Cl}$ under equilibrium conditions in bicarbonate-free Ringer's solution buffered with $10 \mathrm{mM}$ Hepes, $\mathrm{pH} 7.4$, for $2-4 \mathrm{~h}$ at $37^{\circ} \mathrm{C}$ for control and 4PBA-treated cells and at $27^{\circ} \mathrm{C}$ for cells incubated at the $27^{\circ} \mathrm{C}$ condition. Cells were washed three times with $1 \mathrm{ml}$ of ice cold Ringer's solution before addition of $1 \mathrm{ml}$ Ringer's solution with (stimulated) or without (basal) $13.5 \mu \mathrm{M}$ forskolin (Sigma Chemical Co.) at room temperature. The Ringer's solution was changed every $15 \mathrm{~s}$ and counted by liquid scintillation in CytoScint (ICN Research Products, Costa Mesa, CA). Cells were lysed after 3 min with $0.2 \mathrm{~N} \mathrm{NaOH}$ and residual ${ }^{36} \mathrm{Cl}$ was determined by liquid scintillation. Apparent first order rate constants for chloride secretion were determined from three to four independent time courses for each condition using a nonlinear least squares method. Statistical comparison of these rate constants was performed using a two-tailed $t$ test.

Single channel/patch clamp recording. Single channel patch clamp studies were performed in the excised inside-out patch configuration using conventional procedures (19). Recording pipettes were constructed from borosilicate glass capillaries (Garner Glass, Claremont, CA) using a microelectrode puller (PP83; Narishige Scientific Instrument Laboratory, Tokyo, Japan). The pipettes were partially filled with a standard pipette solution and had tip resistance of 2-5 $\mathrm{M} \Omega$. Recording was performed at room temperature $\left(20-22^{\circ} \mathrm{C}\right)$. Single channel currents were recorded with a patch clamp amplifier (Axopatch 200A; Axon Instruments Inc., Foster City, CA), low pass filtered at $1 \mathrm{kHz}$ using an 8-pole Bessel filter, and stored on videotape after pulse code modulation (model PCM-501ES; Sony, Tokyo, Japan). Data were redigitized $(4 \mathrm{kHz})$ for analysis, transferred to a desktop computer, and analyzed using pCLAMP6 (Axon Instruments Inc.).

The bath solution contained (mM): $\mathrm{NaCl}, 140 ; \mathrm{MgCl}_{2}, 2$; EGTA, 1; Hepes, 5; and $\mathrm{CaCl}_{2}, 0.5$ (free $\mathrm{Ca}^{2+} 110 \mathrm{nM}$ as measured by Fura-2), $\mathrm{pH}$ 7.3. The pipette solution contained (mM): $\mathrm{NaCl}, 140 ; \mathrm{CaCl}_{2}, 2$; and Hepes, 5, pH 7.3. All solutions were filtered through $0.2-\mu \mathrm{m}$ filters.

Chloride channels were activated by the addition of the catalytic subunit of protein kinase A (PKA; Promega, Madison, WI) and MgATP at final concentrations of $50 \mathrm{nM}$ and $1 \mathrm{mM}$, respectively. To prevent CFTR channel rundown in excised patches, $1 \mathrm{mM} \mathrm{Mg-ATP}$ was added to the bath solution.

Antibodies. Antisera 169 and 181 directed against human CFTR peptides in the R domain and before NBF-1, respectively, were generated in rabbits and described previously in publications from our laboratory (20). Antiserum 169 was used at a 1:500 dilution for immunocytochemistry and antiserum 181 was used at 1:2,000 dilution for immunoblot detection. The secondary antibody for both immunocytochemistry and immunoblot analyses was a donkey anti-rabbit IgG- horseradish peroxidase conjugate (Amersham, Arlington Heights, IL) used at 1:1,000 dilution for immunocytochemistry and 1:10,000 dilution for immunoblots. Incubation times for both primary antisera and secondary antibodies were $1 \mathrm{~h}$ at room temperature.

Immunoblot analysis. Whole cell lysates were prepared by solubilization with 2 or $10 \%$ SDS at $95^{\circ} \mathrm{C}$ as noted in the figure legends. Protein concentration in the lysates was determined using the BioRad $D_{C}$ assay reagents with bovine plasma $\gamma$-globulin as a standard (Bio-Rad Laboratories, Hercules, CA). Equal amounts of protein were resolved by electrophoresis on 5 or $6 \%$ SDS-polyacrylamide gels. Proteins were transferred to nitrocellulose and immunodetection performed as previously described (20). Nonspecific binding was blocked by incubation of the nitrocellulose with $2 \%$ gelatin. Primary antisera and secondary antibodies were applied in buffer containing $0.4 \%$ bovine serum albumin for $1 \mathrm{~h}$ at room temperature. Detection of immunoreactivity was performed with the ECL chemiluminescence reagent (Amersham) and fluorography. Densitometry of these fluorographs was performed using an image digitizer and software (Ultra-Lum, Inc., Carson, CA) and analyzed using AAB 2-D Main software (Advanced American Biotechnology, Fullerton, CA).

Immunocytochemistry. Cells were grown on coated cover slips in 6-well plates under the indicated conditions in standard media. Cells were fixed in $10 \%$ formalin in phosphate-buffered saline and permeabilized with $95 \%$ methanol in phosphate-buffered saline. Immunocytochemical detection of CFTR with antiserum 169 was performed as above and as previously described (20). Histomark orange and true blue peroxidase (both from Kirkegaard and Perry Laboratories, Gaithersburg, MD) were used according to the manufacturer's protocol to detect positive immunocytochemical reaction. Counterstain, when used, was Nuclear Fast red (Digene, Beltsville, MD) and was applied for 1-1.5 min. Samples on cover slips were dehydrated through sequential ethanol before mounting on slides with Mount Quick (Research Products International, Mount Prospect, IL). Photomicrographs were made using a Zeiss microscope (Zeiss, Oberkochen, Germany) and Kodak (Rochester, NY) T-64 slide film. Immunocytochemistry on control and 4PBA-treated cells was performed using the same antisera dilutions, incubation times, counter-staining times, exposure conditions, and printing conditions.

Reagents. Pharmaceutical grade 4PBA, manufactured by Triple Crown America (Perkasie, PA), was a gift from Dr. Saul W. Brusilow (Department of Pediatrics, The Johns Hopkins Hospital). Reagent grade butyric acid was purchased from Sigma Chemical Co. Glycerol, ACS reagent grade, was purchased from J.T. Baker (Phillipsburg, $\mathrm{NJ}$ ) and was sterilized by autoclaving before use. Nitrocellulose was purchased from Schleicher and Schuell (Keene, NH). Electrophoresis grade chemicals were purchased from Bio-Rad Laboratories. All other reagents were of reagent grade or better.

\section{Results}

4PBA promotes functional correction of cAMP-mediated chloride transport in $C F$ airway epithelial cells. In normal epithelial cells, elevations in cAMP stimulate chloride transport by CFTR via phosphorylation by PKA and ATP binding. This is not observed in epithelial cells from $C F$ patients in response to cAMP or cAMP-stimulating agents. $\triangle$ F508-CFTR forms PKA-activated chloride channels in lipid bilayers (1), in oocytes $(2,3)$, and in the ER membrane (4), but is prevented from reaching the epithelial cell surface (5). To study $\Delta$ F508CFTR trafficking, we chose the IB3-1 cell line, an immortalized CF bronchial epithelial cell line with genotype $\Delta \mathrm{F} 508$ / W1282X (17). As is typical of CF epithelial cells, IB3-1 cells do not increase chloride transport in response to cAMP stimulation (18). The W1282X mutation produces an unstable, and therefore untranslated mRNA (21-24). All CFTR protein in 
Table I. Comparison of Apparent First Order Rate Constants for Chloride Efflux

\begin{tabular}{lccc}
\hline & \multicolumn{2}{c}{$\begin{array}{c}k_{\text {app }}\left(\mathrm{min}^{-1}\right) \text { for } \mathrm{Cl}^{-} \text {efflux } \\
\left(\mathrm{mean}^{2} \mathrm{SEM}\right)\end{array}$} & \\
\cline { 2 - 3 } \multicolumn{1}{c}{ Condition } & Basal & Forskolin (cAMP) & $\begin{array}{c}P \text { value } \\
\text { (two-tailed } t \text { test) }\end{array}$ \\
\hline $37^{\circ} \mathrm{C}$ (control) & $0.258 \pm 0.015$ & $0.291 \pm 0.024$ & 0.39 \\
$100 \mu \mathrm{M} \mathrm{4PBA}, 37^{\circ} \mathrm{C}$ & $0.304 \pm 0.044$ & $0.474 \pm 0.018$ & $0.017^{*}$ \\
$27^{\circ} \mathrm{C}$ & $0.187 \pm 0.019$ & $0.325 \pm 0.016$ & $0.011^{*}$ \\
\hline
\end{tabular}

Apparent first order rate constants of chloride efflux were determined for three to four independent time courses by a nonlinear least squares method. Rate constants were averaged and are expressed as mean \pm SEM for unstimulated (basal) and forskolin-stimulated chloride efflux for each condition of incubation. Statistical significance was determined using a two-tailed $t$ test. $* P<0.05$.

IB3-1 cells is $\Delta$ F508-CFTR which is retained in the ER and is undetectable at the cell surface.

Table I contains the apparent first order rate constants for radioisotopic chloride secretion from untreated and 4PBAtreated IB3-1 cells. As expected, IB3-1 cells grown in control medium at $37^{\circ} \mathrm{C}$ did not demonstrate an increased rate of chloride secretion in response to forskolin treatment. However, IB3-1 cells grown at $27^{\circ} \mathrm{C}$ (as a positive control) or in the presence of $100 \mu \mathrm{M} 4 \mathrm{PBA}$ at $37^{\circ} \mathrm{C}$ for $3 \mathrm{~d}$ demonstrated a 1.6 -fold increase in the apparent first order rate of chloride secretion in response to forskolin. In a separate experiment, treatment of IB3-1 cells with $2 \mathrm{mM} 4$ PBA for $3 \mathrm{~d}$ led to a 1.35-fold increase in the rate of forskolin-stimulated chloride secretion $(0.283 \pm$ $0.023 \mathrm{~min}^{-1}$ stimulated vs. $0.210 \pm 0.021 \mathrm{~min}^{-1}$ basal, mean \pm SEM, $n=3$ in each group, $P=0.079$ by two-tailed $t$ test). These data are consistent with 4PBA facilitating the appearance of cAMP-stimulated chloride channels at the cell surface of CF epithelial cells.

We next confirmed that the observed cAMP-stimulated increases in IB3-1 cell chloride secretion after 4PBA treatment were due to CFTR chloride channels at the cell surface, and not alternative chloride channels. We examined single channel recordings in patches excised from IB3-1 cells grown at $37^{\circ} \mathrm{C}$ in the presence or absence of 4PBA (Table II). To maximize our ability to detect CFTR channels at the cell surface after 4PBA treatment, IB3-1 cells were grown in the presence of a single, high concentration $(2.5 \mathrm{mM})$ of 4PBA for $2 \mathrm{~d}$. These cells demonstrated chloride currents consistent with that of CFTR, namely a PKA-stimulated linear current/voltage profile with $10 \mathrm{pS}$ conductance that was present in $9 / 15$ patches. A representative patch recording and a current/voltage (I/V) plot summarizing these channel data are shown in Fig. 1. The open

Table II. Single Channel Patch Clamp Analysis

\begin{tabular}{lcc}
\hline Cell type & Incubation conditions & $\begin{array}{c}\text { Patches with CFTR } \\
\text { channel activity }\end{array}$ \\
\hline IB3-1 & $37^{\circ} \mathrm{C}$ & $0 / 10^{*}(0 / 15)^{\ddagger}$ \\
IB3-1 & $37^{\circ} \mathrm{C}, 2.5 \mathrm{mM} 4 \mathrm{PBA}$ & $9 / 15^{*}$ \\
IB3-1 & $27^{\circ} \mathrm{C}$ & $54 / 67^{\ddagger}$
\end{tabular}

${ }^{*} P=0.0115$ by two-tailed Fisher exact test. ${ }^{*}$ Data from Egan et al. (19). probability $\left(P_{\mathrm{o}}\right)$ of these channels was $0.201 \pm 0.04$, which is similar to that obtained in IB3-1 cells grown at reduced temperature $(0.21 \pm 0.04)(19)$. This $P_{\mathrm{o}}$ is intermediate to that previously reported for wild-type CFTR (0.35) and $\triangle$ F508-CFTR (0.1) on the cell surface (25), and similar to that of $\Delta \mathrm{F} 508$ CFTR found on the ER membrane (0.16) (4). These comparisons suggest that $\Delta \mathrm{F} 508-\mathrm{CFTR}$ channels in IB3-1 cells retain altered kinetics of chloride conduction, which would not be predicted for the $\mathrm{W} 1282 \mathrm{X}$ allele.

Because these experiments were conducted in an excised patch configuration, we were unable to directly measure channel number. However, the frequency with which we detected CFTR activity in excised patches $(9 / 15)$ is similar to that of IB3-1 cells incubated at reduced temperatures (57/81) (19), transformed fetal human tracheal epithelial cells in culture (56FHTE80 ${ }^{-}$, no known CFTR mutation, 8/12) (19), and in transfected IB3-1 cells stably expressing wild-type CFTR (S9 cells, 8/10) (19). These observations suggest similar channel density in IB3-1 cells after 4PBA treatment as in corrected IB3-1 cells and non-CF tracheal epithelial cells.

The chloride conductance of these channels was blocked by $0.1 \mathrm{mM}$ glibencamide $(n=3)$, but was unaffected by $0.5 \mathrm{mM}$ 4,4' -diisothiocyanatostilbene-2,2'-disulfonic acid (DIDS, $n=$ 2). This response to chloride channel blockers is typical of CFTR chloride channel activity. CFTR channel activity was not observed in plasma membrane patches from IB3-1 cells

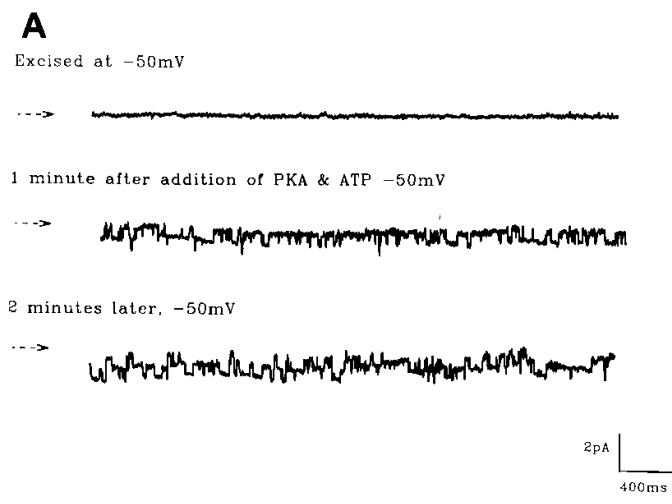

B

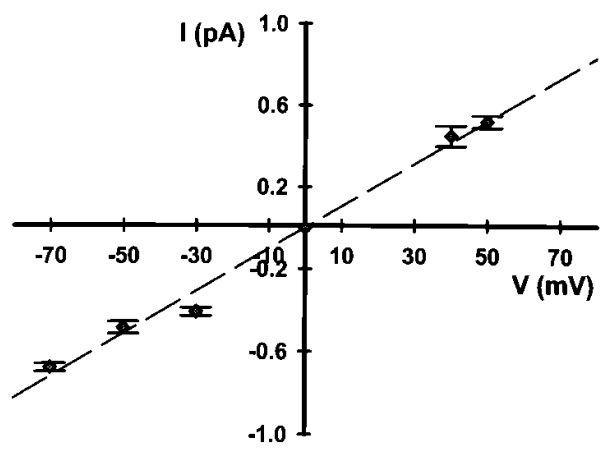

Figure 1. Single channel recordings from IB3-1 cells grown in 4PBA. IB3-1 cells were cultured in the presence of $2.5 \mathrm{mM} 4 \mathrm{PBA}$ for $2 \mathrm{~d}$ before single channel recording performed as described in Methods. $(A)$ A representative patch recording of a CFTR channel. (B) A current/ voltage plot of CFTR channel activity. Each point is the average of at least five determinations. The conductance of these channels was $10.3 \pm 0.05 \mathrm{pS}$ and the open probability was $0.201 \pm 0.04$. 


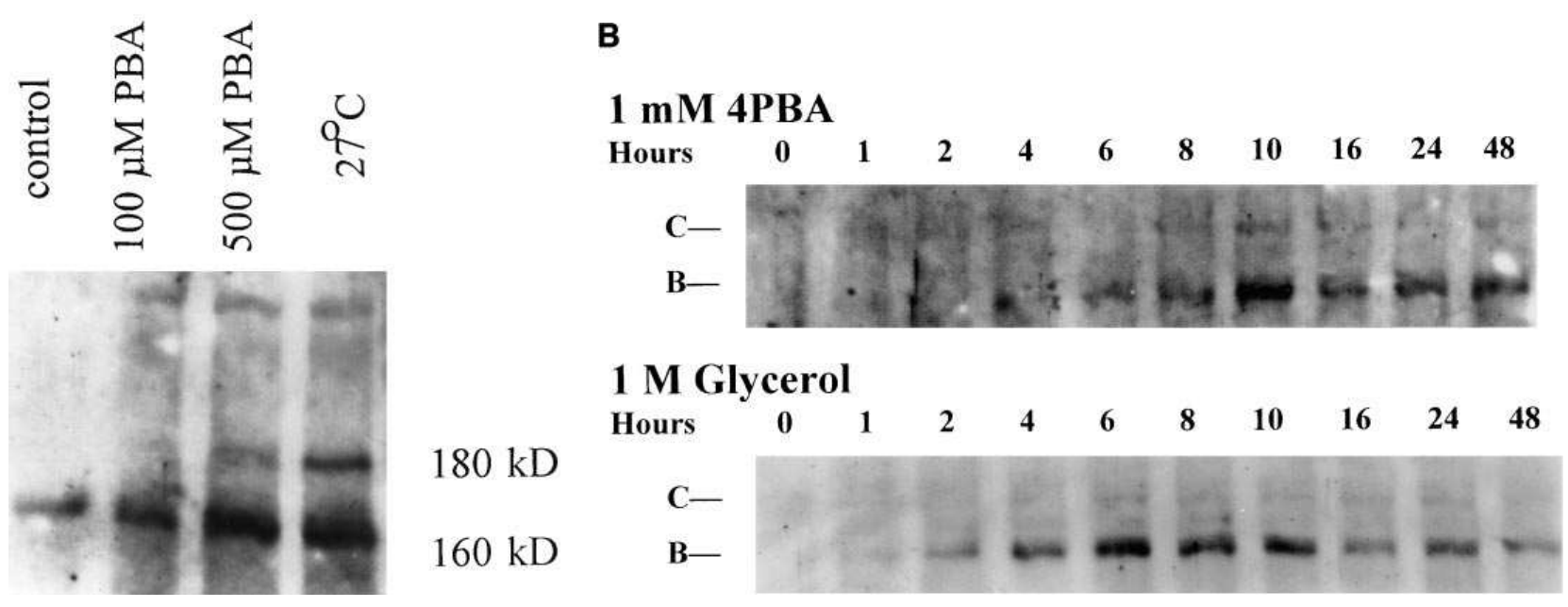

Figure 2. Immunoblot of cell lysates from IB3-1 cells grown in the presence of 4PBA demonstrate shifts in the apparent mobility of CFTR consistent with trafficking through the Golgi apparatus. IB3-1 cells were $(A)$ grown for $3 \mathrm{~d}$ under the indicated condition or $(B)$ grown with $1 \mathrm{mM}$ $4 \mathrm{PBA}$ or $1 \mathrm{M}$ glycerol for the indicated time. Whole cell lysates were prepared by solubilization in $2 \% \mathrm{SDS}$ at $95^{\circ} \mathrm{C}$. $10 \mu \mathrm{g}$ of total protein was resolved on a 5\% SDS-polyacrylamide gel before electrophoretic transfer to nitrocellulose for immunodetection of CFTR as previously described. The primary antiserum was a rabbit anti-prenucleotide binding domain 1 peptide antiserum (antiserum 181) and the secondary antibody was a donkey anti-rabbit horseradish peroxidase conjugate. Immunoreactivity was detected using the ECL reagent as described in Methods.

grown under control conditions at $37^{\circ} \mathrm{C}$ in the absence of 4PBA $(n=10)$. Overall, these channel data in 4PBA-treated IB3-1 cells are similar to those obtained when IB3-1 cells were grown at reduced temperatures (19).

$4 P B A$ treatment leads to higher molecular mass forms of $\triangle F 508-C F T R$. Because it is retained in the ER, $\triangle$ F508-CFTR does not acquire a mature glycosylation pattern indicative of oligosaccharide modification in the Golgi apparatus (5). Wildtype CFTR, as expressed in COS-7 cells, is found as three differentially glycosylated species that can be distinguished by molecular mass: band A (molecular mass $\sim 130 \mathrm{kD}$ ) is unglycosylated, band B (molecular mass $150-170 \mathrm{kD}$ ) is core glycosylated in the ER, and band C (molecular mass 180-190 kD) has a mature glycosylation pattern characteristic of oligosaccharide processing in the Golgi apparatus. In COS-7 cells expressing $\Delta$ F508-CFTR, only band B is observed (5). $\Delta$ F508CFTR in IB3-1 cells shows a similar pattern; there is typically a single immunoreactive band at molecular mass $\sim 160 \mathrm{kD}$ consistent with band $\mathrm{B}$ (Fig. $2 \mathrm{~A}$ ). In some experiments, a species of molecular mass $\sim 140 \mathrm{kD}$ consistent with band A was observed.

We next tested whether 4PBA would induce $\Delta$ F508-CFTR maturation consistent with that of wild-type CFTR's passage through the Golgi apparatus by examining CFTR immunoreactivity on protein immunoblots of IB3-1 cell lysates. In Fig. $2 A$, IB3-1 cells were incubated for $3 \mathrm{~d}$ under control conditions at $37^{\circ} \mathrm{C}$, in control media containing $0.1 \mathrm{mM} 4 \mathrm{PBA}$ at $37^{\circ} \mathrm{C}$, with $0.5 \mathrm{mM} 4 \mathrm{PBA}$ at $37^{\circ} \mathrm{C}$, or in control media at $27^{\circ} \mathrm{C}$. Whole cell lysates were prepared and CFTR was detected by immunoblot analysis using a rabbit antiserum against a peptide $\mathrm{NH}_{2}$-terminal to nucleotide binding domain 1 (antiserum 181) (20) after SDS-PAGE. Band $C$ was readily detected in the $0.5 \mathrm{mM}$ 4PBA and the $27^{\circ} \mathrm{C}$ samples, less readily detected in the $0.1 \mathrm{mM}$ 4PBA sample, and not in the control sample. Densitometric analysis of this experiment suggests that treatment of IB3-1 cells with $0.5 \mathrm{mM} 4 \mathrm{PBA}$ results in approximately fourfold increased total immunoreactive CFTR protein, with approximately one-fourth of that immunoreactivity found as band $\mathrm{C}$. For comparison, incubation at $27^{\circ} \mathrm{C}$ resulted in approximately fivefold increased immunoreactivity with again approximately one-fourth found as band $\mathrm{C}$.

Fig. $2 B$ depicts the time course of the appearance of band $\mathrm{C}$ in IB3-1 cell lysates after treatment with 4PBA or the chemical chaperone glycerol. Total CFTR immunoreactivity, first in the form of band B, began to increase after 2-4 h of exposure to 4PBA or glycerol. Band $\mathrm{C}$ formation was noted at 6 (glycerol) to $8 \mathrm{~h}$ (4PBA). Band $\mathrm{B}$ and band $\mathrm{C}$ expression were both stable for at least $48 \mathrm{~h}$. These kinetics are similar to those published for incubations of heterologous cells expressing $\Delta \mathrm{F} 508$ CFTR at reduced temperatures (12) or in the presence of the chemical chaperone glycerol $(13,14)$. In a parallel experiment, the concentration of 4PBA present in the growth media (measured by high performance liquid chromatography [26]) remained essentially constant at $1 \mathrm{mM}$ over the same 48 -h time course.

Immunocytochemical detection of $\triangle F 508-C F T R$ in $4 P B A$ treated cells. We next visualized $\triangle F 508$-CFTR immunoreactivity after 4PBA treatment in IB3-1 cells. Cells were grown in the absence or presence of $1 \mathrm{mM} 4 \mathrm{PBA}$ for $3 \mathrm{~d}$ at $37^{\circ} \mathrm{C}$. Positive control conditions were IB3-1 cells grown in $1 \mathrm{M}$ glycerol at $37^{\circ} \mathrm{C}$ or at $27^{\circ} \mathrm{C}$. Immunocytochemistry was performed on fixed cells using a rabbit antiserum directed against a CFTR regulatory domain peptide (antiserum 169) (20). Representative data are shown in Fig. 3. Glycerol and $27^{\circ} \mathrm{C}$ increased CFTR immunostaining and were associated with morphologic changes. $1 \mathrm{mM}$ 4PBA uniformly increased CFTR immunostaining without apparent morphologic changes. The effect of 4PBA was dose dependent. In preliminary experiments, cells treated with $<0.1 \mathrm{mM} 4 \mathrm{PBA}$ had no increase in CFTR immunoreactivity, while cells treated with $0.1,0.5,1$, and $10 \mathrm{mM}$ 


\section{Control}

$1 \mathrm{mM} 4-\mathrm{PBA}$

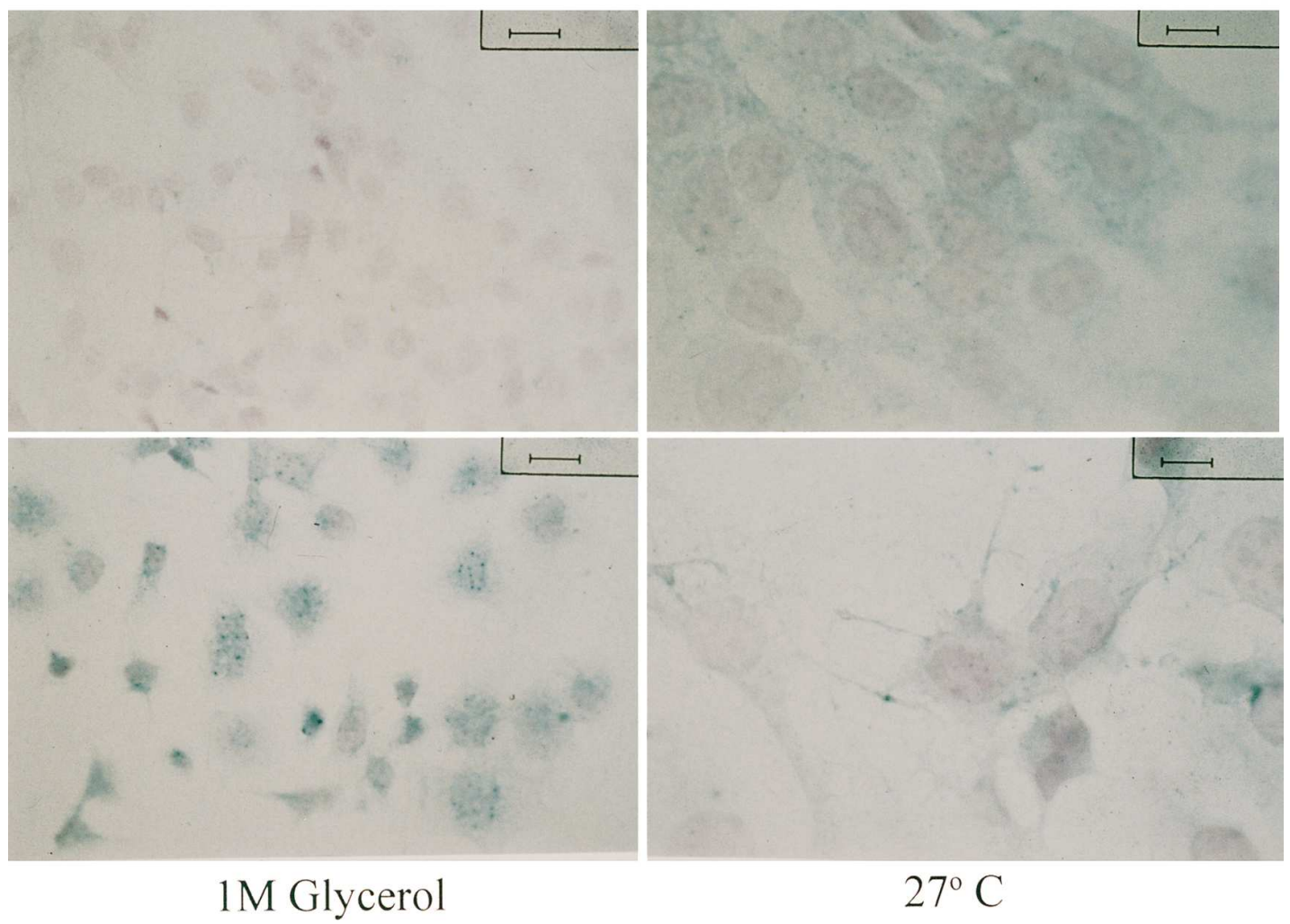

Figure 3. Immunocytochemical detection of CFTR in IB3-1 cells. IB3-1 cells were fixed after $3 \mathrm{~d}$ of exposure to the indicated conditions. CFTR immunoreactivity was detected as described in Methods and appears as a blue stain. The counterstain is Nuclear Fast red. The bar represents 12 $\mu \mathrm{m}$ for the control and glycerol panels, and $6 \mu \mathrm{m}$ for the PBA and $27^{\circ} \mathrm{C}$ panels.

4PBA had qualitatively increasing 4PBA immunoreactivity (data not shown). These data are consistent with 4PBA, increasing expression of $\triangle \mathrm{F} 508-\mathrm{CFTR}$ in a manner similar to that of $1 \mathrm{M}$ glycerol and incubation at reduced temperature. These data are also consistent with our immunoblot data that 4PBA increases CFTR expression in IB3-1 cells.

When IB3-1 cells were grown in $10 \mathrm{mM}$ butyrate, cell death occurred within $24 \mathrm{~h}$, and morphologic changes and decreased growth rate were apparent at $1 \mathrm{mM}$ butyrate. These concentrations of butyrate are lower than those tested in CFPAC cells (5-25 mM), a pancreatic acinar carcinoma cell line homozygous for $\Delta$ F508-CFTR (10), suggesting that IB3-1 cells are more sensitive to toxic effects of butyrate than CFPAC cells.

Primary cultures of CF nasal epithelial cells also respond to $4 P B A$. Nasal epithelial cells from CF patients in primary culture also respond to $4 \mathrm{PBA}$ treatment in vitro. Fig. 4 shows an immunoblot from an experiment similar to that shown for IB3-1 cells in Fig. 2. Primary cultures of nasal epithelial cells from a CF patient (genotype $\Delta$ F508/unidentified mutation) were grown in control media in the absence or presence of 2.5 or $5 \mathrm{mM} 4 \mathrm{PBA}$ for $6 \mathrm{~d}$ in culture at $37^{\circ} \mathrm{C}$. Only bands $\mathrm{A}$ and $\mathrm{B}$ (molecular masses $\sim 130$ and $\sim 170 \mathrm{kD}$ ) were observed for untreated cells and cells grown in the presence of $2.5 \mathrm{mM} 4 \mathrm{PBA}$. Band $\mathrm{C}(\sim 190 \mathrm{kD})$, as well as bands $\mathrm{A}$ and $\mathrm{B}$, was observed for cells grown in the presence of $5 \mathrm{mM} 4 \mathrm{PBA}$. Densitometry of this experiment suggests a 2.5 -fold increase in immunoreactive CFTR protein (bands $\mathrm{A}+\mathrm{B}+\mathrm{C}$ ) after treatment with
$5 \mathrm{mM} 4 \mathrm{PBA}$, with band B having twice as much CFTR immunoreactivity as band $\mathrm{C}$ after treatment with $5 \mathrm{mM} 4 \mathrm{PBA}$.

Although higher concentrations of $4 \mathrm{PBA}$ are required to increase band $\mathrm{C}$ expression in the primary nasal epithelia than in IB3-1 cells, these results are similar to those seen in IB3-1 cells. Therefore, these data suggest that the 4PBA-induced maturation of $\triangle F 508-C F T R$ is neither an artifact of cell transformation nor an effect of 4PBA on the W1282X allele present in IB3-1 cells. While the identity of the second mutant CFTR allele in these primary nasal epithelial cells is unknown, we do know that it is not W1282X, $\Delta$ F508, N1303K, G542X, G551D, or R553X. These alleles were part of this patient's screen during genotype determination. However, it remains unclear why higher concentrations of 4PBA were required to observe this effect in primary nasal epithelial cells than in immortalized IB3-1 cells.

4PBA treatment also resulted in an increase in CFTR immunoreactivity in primary nasal epithelial cells from a patient with genotype $\Delta \mathrm{F} 508 / \Delta \mathrm{F} 508$ (Fig. 5). The effect of 4PBA was again dose dependent; treatment of these cells with concentrations of 4PBA $<1 \mathrm{mM}$ showed little increase in CFTR immunoreactivity (data not shown). These data further suggest that 4PBA stimulates expression of $\triangle F 508$-CFTR and not an alternative mutant allele present in IB3-1 cells or in the nasal epithelial cells assayed in Fig. 4.

$4 P B A$ does not alter phenotype in cells expressing functional $C F T R$. In a control experiment, we also assessed the influence 


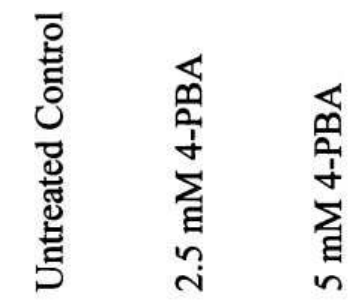

$200 \mathrm{kD}$

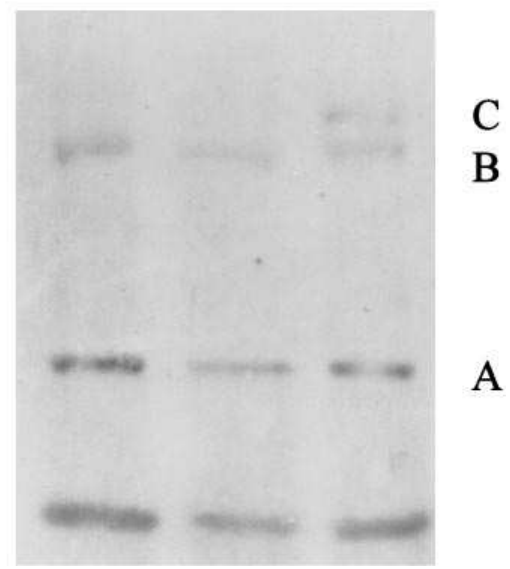

Figure 4. Immunoblot of cell lysates of 4PBA-treated primary nasal epithelium from a CF patient demonstrates molecular mass shifts consistent with oligosaccharide maturation. Nasal polyp epithelial cells from a CF patient with genotype $\Delta \mathrm{F} 508$ /unknown were grown in primary culture with the indicated concentration of 4PBA for $6 \mathrm{~d}$ at $37^{\circ} \mathrm{C}$. Cellular lysates were prepared by solubilization with $10 \%$ SDS at $95^{\circ} \mathrm{C} .16 \mu \mathrm{g}$ of total protein was resolved on a $6 \%$ SDS-polyacrylamide gel before electrophoretic transfer to nitrocellulose for immunodetection of CFTR as previously described in the legend to Fig. 2. of 4PBA on IB3-1 cells that had been stably transfected with a functional CFTR allele (C38 cells) (27). Unlike the parent IB3-1 cells, C38 cells demonstrate a "rescued" phenotype, namely they demonstrate a stimulation of chloride secretion in response to forskolin, and CFTR-like channel activity on the plasma membrane. Incubation of C38 cells with $0.5 \mathrm{mM}$ did not affect the rate of forskolin-stimulated chloride secretion; both control and 4PBA-treated C38 cells had an $\sim 1$.4-fold increase in rate of chloride efflux in response to forskolin. Thus, 4PBA did not alter the phenotype of $\triangle F 508$-CFTR-containing cells in the presence of a functional CFTR allele. This magnitude of stimulation of chloride secretory rate in untreated C38 cells is similar to the parent IB3-1 cells after 4PBA treatment.

One possible explanation for not observing an additional effect of 4PBA in C38 cells is that the expression of a functional CFTR allele would cause downregulation of $\triangle F 508$ CFTR expression, and therefore remove the target of 4PBA action. Another explanation is that the phenotypic presence of $\triangle$ F508-CFTR is masked by presence of functional CFTR activity.

\section{Discussion}

Mechanism. Collectively, these data suggest that an approved pharmaceutical agent, 4PBA, at clinically relevant concentrations (26), restores $\triangle$ F508-CFTR to the normal pathway for trafficking to the plasma membrane. The experiments reported here do not distinguish between the possible mechanisms of 4PBA action.

4PBA was developed as a plasma ammonia scavenger for treatment of patients with urea cycle defects $(26,28)$. During early clinical trails of 4PBA, it was observed that circulating fe-

\section{Control}

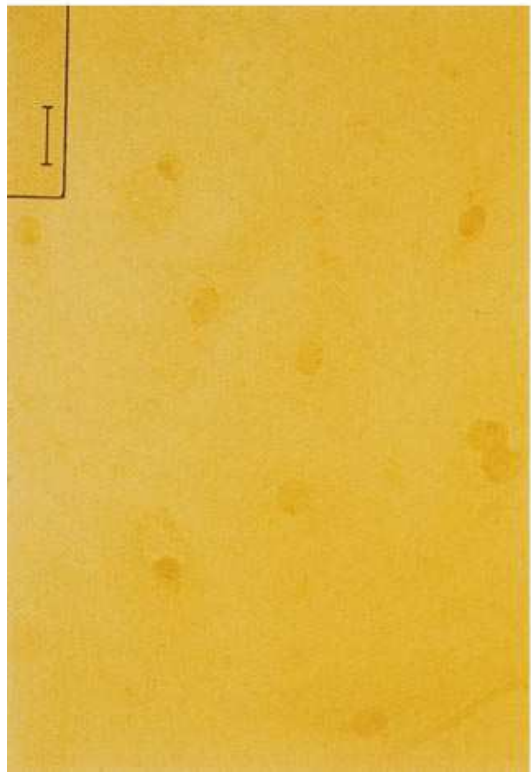

$5 \mathrm{mM} 4-\mathrm{PBA}$

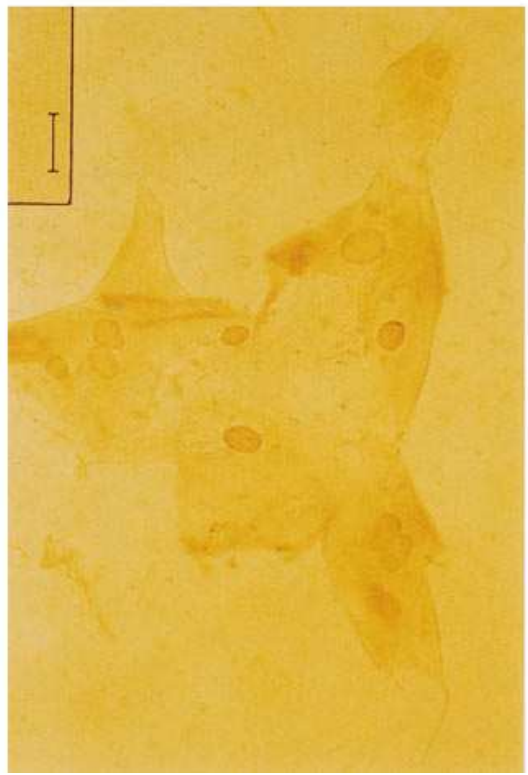

$5 \mathrm{mM}_{4}-\mathrm{PBA}^{\circ}$

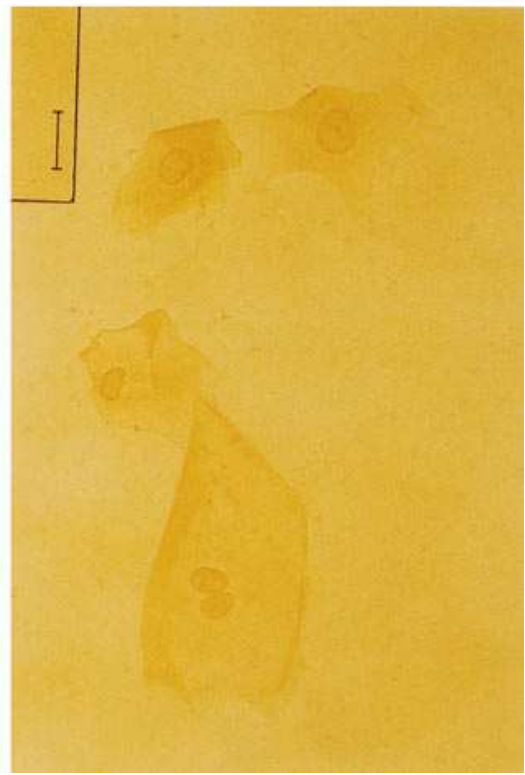

Figure 5. Immunocytochemical detection of CFTR in primary nasal epithelial cells from a CF patient. Primary nasal epithelial cells from a CF patient with genotype $\Delta \mathrm{F} 508 / \Delta \mathrm{F} 508$ were grown in growth media without $4 \mathrm{PBA}$ (control) or containing $5 \mathrm{mM} 4 \mathrm{PBA}$ for $3 \mathrm{~d}$ at $37^{\circ} \mathrm{C}$. Cells were fixed with $10 \%$ buffered formalin and permeabilized with $95 \%$ methanol before immunocytochemical detection of CFTR. The primary antiserum was a rabbit anti-human CFTR regulatory domain peptide antiserum (antiserum 169) and the secondary antibody was a donkey anti-rabbit IgG-horseradish peroxidase conjugate. Immunoreactivity was detected with Histomark orange (brown positive reaction product) without a counterstain as described in Methods. The bar represents $6 \mu \mathrm{m}$. 
tal hemoglobin increased in these patients (15). Therefore, subsequent clinical trials using 4PBA to raise fetal hemoglobin levels in patients with hemoglobinopathies were undertaken (29). 4PBA is also being used to promote differentiation of malignant cells in vivo and in vitro (30). The mechanism by which 4PBA raises circulating fetal hemoglobin and causes differentiation of tumor cells is different from its mechanism of action as a plasma ammonia scavenger and involves transcriptional upregulation of the relevant genes (30). Both 4PBA and its initial metabolite, phenylacetate (PAA), act to increase fetal hemoglobin levels by increasing transcription of $\gamma$-globin mRNA while decreasing transcription of $\beta$-globin mRNA (15). This action is similar to that of the transcriptional regulator butyrate (15).

Since 4PBA is an analogue of butyrate, a known transcriptional regulator of CFTR expression (10), it is reasonable to hypothesize that 4PBA increases transcription of the $\Delta \mathrm{F} 508$ CFTR allele. As a transcriptional regulator, 4PBA would increase levels of $\Delta \mathrm{F} 508-\mathrm{CFTR}$ protein, and by mass action, would force some $\Delta \mathrm{F} 508-\mathrm{CFTR}$ to bypass quality control in the ER.

This mechanism is consistent with the observations that butyrate itself can induce cAMP-responsive chloride secretion in a $\Delta$ F508-homozygous pancreatic acinar cell line (10). Our data are also consistent with 4PBA increasing the amount of $\Delta$ F508CFTR protein produced; in the immunoblot experiments (Figs. 2 and 4) increased CFTR immunoreactivity was observed in the 4PBA-treated samples when equal amounts of cell lysate protein were assayed. Increased CFTR immunoreactivity was also observed by immunocytochemistry after 4PBA treatment (Figs. 3 and 5).

Confirmation of this mechanism of $4 \mathrm{PBA}$ action will require direct quantification of CFTR mRNA. CFTR mRNA is present at very low levels in the cells of the respiratory epithelia, typically below the level of detection by standard quantitative techniques such as Northern analysis and ribonuclease protection. Direct quantification of CFTR mRNA by either of these methods in untreated respiratory epithelial cells has not been published. The best estimates of CFTR mRNA copy number, determined by semiquantitative reverse-transcriptase polymerase chain reaction experiments, estimate that one to two copies of CFTR mRNA are present per cell (31). However, this method is insensitive to less than twofold differences in transcript level (31). We have attempted to directly measure CFTR mRNA in IB3-1 cells by ribonuclease protection using a probe that detects CFTR mRNA in kidney (32), and with two other probes constructed in our laboratory, but were unable to reproducibly detect CFTR mRNA after treatment with $1 \mathrm{mM}$ 4PBA. This suggests that CFTR mRNA levels remain low in IB3-1 cells even after 4PBA treatment.

Butyrate and 4PBA have effects in IB3-1 cells that are qualitatively different from one another. IB3-1 cells treated with 1-2 mM 4PBA are healthy, grow at a similar rate and with a similar morphology to control cells, and express CFTR channel activity at the plasma membrane. Equimolar concentrations of butyrate cause morphologic changes in IB3-1 cells with rounding of cells and decreased growth rate. This suggests that 4PBA and butyrate may have different toxicity profiles and dose-response relationships. Our observations with 4PBA similarly differ from published observations with butyrate in $\Delta$ F508-CFTR transfected C-127 cells; band C (the $\sim 180-\mathrm{kD}$ mature glycosylated species of CFTR) was not observed after
$5 \mathrm{mM}$ butyrate treatment for $24 \mathrm{~h}$ despite a massive increase in $\Delta$ F508-CFTR mRNA as demonstrated by Northern analysis (10). In our experiments in IB3-1 cells, we were not able to assess the effect of butyrate treatment at millimolar concentrations because such treatments were associated with changes in cellular morphology and cell death. While 4PBA may act as a butyrate analogue to increase transcription of CFTR, the improvement with respect to toxicity at similar concentrations suggests that the mechanism of action of 4PBA may not be limited to increasing $\Delta$ F508-CFTR transcription.

Our data in primary nasal epithelia also differ from those of Cheng et al. (10) with respect to primary nasal epithelia. $5 \mathrm{mM}$ 4PBA led to formation of band C (Fig. 4) and increased immunoreactive CFTR protein (Fig. 5) in our experiments. Our cells were grown on solid supports, and we did not assess the electrolyte transport function of these cells. Cheng et al. (10) grew primary nasal epithelia from $\mathrm{CF}$ patients on semipermeable supports in Ussing chambers to generate a monolayer with tight junctions. In this system, they did not detect increases in cAMP-stimulated current indicative of chloride transport after treatment with up to $300 \mathrm{mM}$ butyrate. There are a number of possible explanations for these differences in results. The simplest explanation is that 4PBA and butyrate may have overlapping, but not identical effects on nasal epithelial cells, as is suggested above. Demonstration of the effects of 4PBA on polarized epithelial monolayers is under investigation.

Our data are qualitatively similar to those obtained when cells expressing $\Delta$ F508-CFTR are incubated with $1 \mathrm{M}$ or $10 \%$ glycerol (Figs. $2 B$ and 3$)(13,14)$. Glycerol stabilizes thermally labile proteins during purification and storage, and may act by stabilizing an intrinsically thermolabile $\Delta$ F508-CFTR such that a "partially unfolded" conformation is no longer recognized by the ER quality control mechanism. Glycerol has been shown by several groups to significantly improve processing and trafficking of $\Delta$ F508-CFTR similar to growth at $25-27^{\circ} \mathrm{C}(12,19)$.

Growth at reduced temperatures leads to thermal stabilization of cellular contents. The degree of thermal stabilization that is achieved by a $10^{\circ} \mathrm{C}$ temperature decrease is $\sim 2-3 \mathrm{kcal} /$ $\mathrm{mol} ; 2-3 \mathrm{kcal} / \mathrm{mol}$ is approximately the energy of either one or two hydrogen bonds or a small number of hydrophobic interactions. Phenylalanine 508 resides in a region of predicted $\beta$-sheet secondary structure in nucleotide binding fold 1 of CFTR $(33,34)$. A peptide corresponding to CFTR nucleotide binding domain 1 (NBD-1, residues 404-589) is more readily denatured by guanidinium or increasing temperature when phenylalanine 508 is deleted (35). The mutant peptide is also more likely to form aggregates than the wild-type NBD-1 peptide (35). These observations are consistent with a thermodynamic destabilization of CFTR by the deletion of F508.

Glycerol is considered a member of the chemical chaperone class of compounds because of its thermal stabilization properties. Structurally, 4PBA and glycerol are not particularly similar. One can speculate that high concentrations of glycerol would increase the viscosity of the aqueous environment which would slow molecular motion and decrease the rate of denaturation. 4PBA might provide thermal stabilization by favoring the formation of a missing hydrogen bond or hydrophobic interaction. It also might directly disrupt the interaction of $\triangle \mathrm{F} 508$-CFTR and a molecular chaperone such as hsp70 (7) or calnexin (6). Alternatively, 4PBA might act as a transcriptional regulator of a protein involved in the ER quality control system. Alteration of expression of this hypotheti- 
cal agent would influence the ability of the cell to block $\Delta$ F508CFTR trafficking.

It is also as yet unclear whether the active species of 4PBA is 4PBA, one of its metabolites, or both. As in the case for the urea cycle disorders where $4 \mathrm{PBA}$ is a prodrug and phenylacetate (the product of $4 \mathrm{PBA} \beta$-oxidation) is the active species for scavenging ammonia (26), phenylacetate may be the active compound for normalizing $\triangle$ F508-CFTR trafficking. Arguing against phenylacetate as the active compound is the lack of conversion of $4 \mathrm{PBA}$ to phenylacetate in the culture media of IB3-1 cells over a 2-d incubation.

Therapy. Manipulation of aberrant intracellular $\Delta \mathrm{F} 508-$ CFTR trafficking has great promise as a pharmacologic treatment for the majority of CF patients. This approach, inducing the expression of a functional native protein by correcting its intracellular trafficking, circumvents many of the problems associated with other strategies for restoration of CFTR function, namely gene delivery systems and long-term persistence. The concentrations of 4PBA used in these experiments are similar to those routinely achieved in the plasma of patients who receive 4PBA therapy for urea cycle disorders (28). These factors make the use of 4PBA attractive as a potential pharmacologic therapy in CF patients who have at least one $\Delta \mathrm{F} 508$ CFTR allele.

Conclusions. 4PBA promotes escape of a fraction of $\Delta$ F508-CFTR from the ER and its appearance at the plasma membrane in cells derived from the respiratory epithelia of $\mathrm{CF}$ patients. This cell surface $\Delta$ F508-CFTR exists as linear, $10 \mathrm{pS}$ chloride channel activated by PKA and ATP. The mechanism by which 4PBA acts is unclear, but preliminary data suggest that 4PBA may have overlapping but different overall effects than butyric acid, a known regulator of CFTR gene expression. Clinical trials will be required to determine the safety and utility of 4PBA as a therapy for CF patients.

\section{Acknowledgments}

The authors thank Dr. David Tunkel for providing the surgical nasal polyp specimens, Ms. Dawn Martin and Mr. Matthew Harley for expert technical assistance, Ms. Ellen Gordes and Dr. Saul Brusilow for measuring 4PBA concentrations in growth media, and Dr. Ada Hamosh for helpful discussions.

This work was supported by National Institutes of Health grant P01 HL-51811 (to P.L. Zeitlin), National Institutes of Health grant HL-03023 and the Cystic Fibrosis Foundation (to M.E. Egan), and a Leroy Matthews Physician Scientist Award from the Cystic Fibrosis Foundation to R.C. Rubenstein.

\section{References}

1. Li, C., M. Ramjeesingh, E. Reyes, T. Jensen, X. Chang, J.M. Rommens, and C.E. Bear. 1993. The cystic fibrosis mutation delta F508 does not influence the chloride channel activity of CFTR. Nat. Genet. 3:311-316.

2. Bear, C.E., F. Duguay, A.L. Naismith, N. Kartner, J.W. Hanrahan, and J.R. Riordan. 1991. $\mathrm{Cl}^{-}$channel activity in Xenopus oocytes expressing the cystic fibrosis gene. J. Biol. Chem. 266:19142-19145.

3. Cunningham, S.A., R.T. Worrell, D.J. Benos, and R.A. Frizzell. 1992. cAMP-stimulated ion currents in Xenopus oocytes expressing CFTR cRNA. Am. J. Physiol. 262:C783-C788.

4. Pasyk, E.A., and J.K. Foskett. 1995. Mutant delta F508 cystic fibrosis transmembrane conductance regulator $\mathrm{Cl}^{-}$channel is functional when retained in endoplasmic reticulum of mammalian cells. J. Biol. Chem. 270:12347-12350.

5. Cheng, S.H., R.J. Gregory, J. Marshall, S. Paul, D.W. Souza, G.A. White, C.R. O'Riordan, and A.E. Smith. 1990. Defective intracellular transport and processing of CFTR is the molecular basis of most cystic fibrosis. Cell. 63:827-834.

6. Pind, S., J.R. Riordan, and D.B. Williams. 1994. Participation of the en- doplasmic reticulum chaperone calnexin (p88, IP90) in the biogenesis of the cystic fibrosis transmembrane conductance regulator. J. Biol. Chem. 269:1278412788.

7. Yang, Y., S. Janich, J.A. Cohn, and J.M. Wilson. 1993. The common variant of cystic fibrosis transmembrane conductance regulator is recognized by hsp70 and degraded in a pre-Golgi nonlysosomal compartment. Proc. Natl. Acad. Sci. USA. 90:9480-9484.

8. Jensen, T.J., M.A. Loo, S. Pind, D.B. Williams, A.L. Goldberg, and J.R. Riordan. 1995. Multiple proteolytic systems, including the proteasome, contribute to CFTR processing. Cell. 83:129-135.

9. Ward, C.L., S. Omura, and R.R. Kopito. 1995. Degradation of CFTR by the ubiquitin-proteasome pathway. Cell. 83:121-127.

10. Cheng, S.H., S.L. Fang, J. Zabner, J. Marshall, S. Piraino, S.C. Schiavi, D.M. Jefferson, M.J. Welsh, and A.E. Smith. 1995. Functional activation of the cystic fibrosis trafficking mutant deltaF508-CFTR by overexpression. Am. J. Physiol. 268:L615-L624.

11. Perrine, S.P., G.D. Ginder, D.V. Faller, G.H. Dover, T. Ikuta, H.E. Witkowska, S.-P. Cai, E.P. Vichinsky, and N.F. Oliveri. 1993. A short-term trial of butyrate to stimulate fetal-globin-gene expression in the $\beta$-globin disorders. $N$. Engl. J. Med. 328:81-86.

12. Denning, G.M., M.A. Anderson, J.F. Amara, J. Marshall, A.E. Smith, and M.J. Welsh. 1992. Processing of mutant cystic fibrosis transmembrane regulator is temperature-sensitive. Nature. 358:761-764.

13. Brown, C.R., L.Q. Hong-Brown, J. Biwersi, A.S. Verkman, and W.J. Welch. 1996. Chemical chaperones correct the mutant phenotype of the deltaF508 cystic fibrosis transmembrane conductance regulator protein. Cell Stress \& Chaperones. 1:117-125.

14. Sato, S., C.L. Ward, M.E. Krouse, J.J. Wine, and R.R. Kopito. 1996. Glycerol reverses the misfolding phenotype of the most common cystic fibrosis mutation. J. Biol. Chem. 271:635-638.

15. Dover, G.J., S. Brusilow, and D. Samid. 1992. Increased fetal hemoglobin in patients receiving sodium 4-phenylbutyrate. N. Engl. J. Med. 327:569-570.

16. Chen, W.Y., E.C. Bailey, S.L. McCune, J.Y. Dong, and T.M. Townes. 1997. Reactivation of silenced, virally transduced genes by inhibitors of histone deacetylase. Proc. Natl. Acad. Sci. USA. 94:5798-5803.

17. Zeitlin, P.L., L. Lu, J. Rhim, G. Cutting, G. Stetten, K.A. Kieffer, R. Craig, and W.B. Guggino. 1991. A cystic fibrosis bronchial epithelial cell line: immortalization by adeno-12-SV40 infection. Am. J. Respir. Cell Mol. Biol. 4: 313-319.

18. Trapnell, B.C., P.L. Zeitlin, C.S. Chu, K. Yoshimura, H. Nakamura, W.B. Guggino, J. Bargon, T.C. Banks, W. Dalemans, A. Pavirani, et al. 1991. Down-regulation of cystic fibrosis gene mRNA transcript levels and induction of the cystic fibrosis chloride secretory phenotype in epithelial cells by phorbol ester. J. Biol. Chem. 266:10319-10323.

19. Egan, M.E., E.M. Schwiebert, and W.B. Guggino. 1995. Differential expression of ORCC and CFTR induced by low temperature in CF airway epithelial cells. Am. J. Physiol. 268:C243-C251.

20. McGrath, S.A., A. Basu, and P.L. Zeitlin. 1993. Cystic fibrosis gene and protein expression during fetal lung development. Am. J. Respir. Cell Mol. Biol. 8:201-208.

21. Hamosh, A., B.J. Rosenstein, and G.R. Cutting. 1992. CFTR nonsense mutations G542X and W1282X associated with severe reduction of CFTR mRNA in nasal epithelial cells. Hum. Mol. Genet. 1:542-544.

22. Howard, M., R.A. Frizzell, and D.M. Bedwell. 1996. Aminoglycoside antibiotics restore CFTR function by overcoming premature stop mutations. Nat. Med. 2:467-469.

23. Dietz, H.C., and A. Hamosh. 1996. Letter to the editor. Nat. Med. 2:608.

24. Bedwell, D.M., M. Howard, and R.A. Frizzell. 1996. Letter to the editor. Nat. Med. 6:608-609.

25. Dalemans, W., P. Barbry, G. Champigny, S. Jallat, K. Dott, D. Dreyer, R.G. Crystal, A. Pavirani, J.-P. Lecocq, and M. Lazdunski. 1991. Altered chloride channel kinetics associated with the deltaF508 cystic fibrosis mutation. $\mathrm{Na}$ ture. 354:526-528.

26. Brusilow, S.W. 1991. Phenylacetylglutamine may replace urea as a vehicle for waste nitrogen excretion. Pediatr. Res. 29:147-150.

27. Egan, M., T. Flotte, S. Afione, R. Solow, P.L. Zeitlin, B.J. Carter, and W.B. Guggino. 1992. Defective regulation of outwardly rectifying $\mathrm{Cl}^{-}$channels by protein kinase A corrected by insertion of CFTR. Nature. 358:581-584.

28. Maestri, N.E., S.W. Brusilow, D.B. Clissold, and S.S. Bassett. 1996. Long-term treatment of girls with ornithine transcarbamylase deficiency. $N$. Engl. J. Med. 335:855-859.

29. Collins, A.F., H.A. Pearson, P. Giardina, K.T. McDonagh, S.W. Brusilow, and G.J. Dover. 1995. Oral sodium phenylbutyrate therapy in homozygous beta thalassemia: a clinical trial. Blood. 85:43-49.

30. Carducci, M.A., J.B. Nelson, K.M. Chan-Tack, S.R. Ayyagari, W.S. Sweatt, P.A. Campbell, W.G. Nelson, and J.W. Simons. 1996. Phenylbutyrate induces apoptosis in human prostate cancer and is more potent than phenylacetate. Clin. Cancer Res. 2:379-387.

31. Trapnell, B.C., C.-S. Chu, P.K. Paakko, T.C. Banks, K. Yoshimura, V.J. Ferrans, M.S. Chernick, and R.G. Crystal. 1991. Expression of the cystic fibrosis transmembrane conductance regulator gene in the respiratory tract of normal individuals and individuals with cystic fibrosis. Proc. Natl. Acad. Sci. USA. 88: 
6565-6569.

32. Morales, M.M., T.P. Carroll, T. Morita, E.M. Schwiebert, O. Devuyst, P.D. Wilson, A.G. Lopes, B.A. Stanton, H.C. Dietz, G.R. Cutting, and W.B. Guggino. 1997. Both the wild type and a functional isoform of CFTR are expressed in kidney. Am. J. Physiol. 270:F1038-F1048.

33. Thomas, P.J., and P.L. Pedersen. 1993. Effects of the deltaF508 mutation on the structure, function, and folding of the first nucleotide-binding domain of CFTR. J. Bioenerg. Biomembr. 25:11-19.
34. Thomas, P.J., J.S. Shenbagamurthi, J.M. Hullihen, and P.L. Pedersen. 1992. The cystic fibrosis transmembrane conductance regulator: effects of the most common cystic fibrosis-causing mutation on the secondary structure and stability of a synthetic peptide. J. Biol. Chem. 267:5727-5730.

35. Qu, B.-H., and P.J. Thomas. 1996. Alteration of the cystic fibrosis transmembrane conductance regulator folding pathway: effects of the deltaF508 mutation on the thermodynamic stability and folding yield of NBD1. J. Biol. Chem. 271:7261-7264. 